\title{
Signal propagation and neuronal avalanches analysis in networks of formal neurons
}

\author{
Mauricio Girardi-Schappo ${ }^{1 *}$, Marcelo HR Tragtenberg ${ }^{1}$, Osame Kinouchi ${ }^{2}$ \\ From Twentieth Annual Computational Neuroscience Meeting: CNS*2011 \\ Stockholm, Sweden. 23-28 July 2011
}

To study neurons with computational tools, one may call upon, at least, two different approaches: (i) Hodgkin-Huxley like neurons [1] (i.e. biological neurons) and (ii) formal neurons (e.g. Hindmarsh-Rose (HR) model [2], Kinouchi-Tragtenberg (KT) model [3], etc). Formal neurons may be represented by ordinary differential equations (e.g. HR), or by maps, which are dynamical systems with continuous state variables and discrete time dynamics (e.g. KT). A few maps had been proposed to describe neurons [3-10]. Such maps provide one with a number of computational advantages [10], since there is no need to set any precision on the integration variable, which leads to better performance in the calculations.

An extended KT neuron model, here called $\mathrm{KTz}$ model, has been studied in [4] and [5], may be supplied with a Chemical Synapse Map (CSM) in order to study interacting neurons in a lattice, in the framework of coupled map lattices. KTz model presents most of the standard behavior of excitable cells like fast spiking, regular spiking, bursting, plateau action potentials and adaptation phenomena, and the CSM is in good agreement with some standard functions used to model postsynaptic currents, like the alpha function or the doubleexponential function [4]. Preliminary results indicate antiferromagnetic oscillatory behavior or plane wave behavior in KTz neurons coupled with inhibitory CSM on a square lattice.

Besides, many systems in nature are characterized by complex behavior where large cascades of events, named avalanches, unpredictably alternate with periods of little activity (e.g. snow avalanches, earthquakes, etc). Avalanches are described by power law distributions

\footnotetext{
* Correspondence: girardi.s@gmail.com

'Departamento de Física, Universidade Federal de Santa Catarina,

Florianópolis, SC, 88040-970, Brazil

Full list of author information is available at the end of the article
}

and when the branching parameter equals to unity, the system is said to be a self-organized critical (SOC) system [13]. These have been observed for neuronal activity in vitro $[11,12]$. And since both SOC systems and neuronal activity show large variability, long-term stability and memory capabilities, networks of neurons have been proposed to be SOC systems. This hypothesis was tested in [13], where they made comparisons among in vivo recordings using Local Field Potentials in three macaque monkeys performing a short term memory task and three different well-established subsampled SOC models (e.g. Sandpile model, Random Neighbour Sandpile model and Forest Fire model). Some similar comparison has been done in [14] with in vivo data from fourteen rats and a cellular automaton developed by the authors.

We claim that still no simulation has been made to detect whether formal or realistic neuron models can evolve naturally to a SOC state, in a full or subsampled network. Our simulations are made with $\mathrm{KTz}$ model, which is a formal neuron, but keeps the usual behaviors of living cells, connected through CSM on a square lattice. We divided the work into two parts: (i) the analysis of network itself and how it evolves with time from a given initial state, varying its parameters and (ii) the analysis of the data generated by a network of silent cells, stimulated at random sites, trying to resemble the SOC models above. We compare these second part results with the experimental ones presented in [11-13].

\section{Author details \\ ${ }^{1}$ Departamento de Física, Universidade Federal de Santa Catarina, Florianópolis, SC, 88040-970, Brazil. ²Faculdade de Filosofia, Ciências e Letras de Ribeirão Preto, Universidade de São Paulo, Ribeirão Preto, SP, Brazil.}

Published: 18 July 2011 


\section{References}

1. Hodgkin A, Huxley A: A quantitative description of membrane current. J Physiol 1952, 117(4):500-544.

2. Hindmarsh JL, Rose RM: A model of neuronal bursting. Proc $R$ Soc Lond $B$ Biol Sci 1984, 221:87-102.

3. Kinouchi O, Tragtenberg MHR: Modeling neurons by simple maps. Int $\mathrm{J}$ Bifurcat Chaos 1996, 6:2343-2360.

4. Kuva SM, Lima GF, Kinouchi O, Tragtenberg MHR, Roque AC: A minimal model for excitable and bursting elements. Neurocomputing 2001, 3840:255-261.

5. Copelli M, Tragtenberg MHR, Kinouchi O: Stability diagrams for bursting neurons. Physica A 2004, 342:263-269.

6. Chialvo DR: Generic excitable dynamics on a two-dimensional map. Chaos Solit Fract 1995, 5:461-479.

7. Rulkov NF: Modeling of spiking-bursting neuronal behavior using twodimensional map. Phys Rev E 2002, 65:041922.

8. Cazelles B, Courbage M, Rabinovich M: Anti-phase regularization. Europhys Lett 2001, 56:504-509.

9. Laing $C R$, Longtin $A$ : A two variable model of somaticdendritic interactions. Bull Math Biol 2002, 64:829-860.

10. Izhikevich EM, Hoppensteadt F: Classification of bursting mappings. Int J Bifurcat Chaos 2004, 14(11):3847-3854.

11. Beggs JM, Plenz D: Neuronal avalanches in neocortical circuits. J Neurosci 2003, 23(35):11167-11177.

12. Beggs JM, Plenz D: Neuronal avalanches are diverse and precise activity patterns that are stable for many hours in cortical slice cultures. $J$ Neurosci 2004, 24(22):5216-5229.

13. Priesemann V, Munk MHJ, Wibral M: Subsampling effects in neuronal avalanche. BMC Neurosci 2009, 10:40

14. Ribeiro TL, Copelli M, Caixeta F, Belchior H, Chialvo DR, Nicolelis MAL, Ribeiro S: Spike avalanches exhibit universal dynamics across the sleepwake cycle. PLoS One 2010, 5(11):e14129.

doi:10.1186/1471-2202-12-S1-P172

Cite this article as: Girardi-Schappo et al: Signal propagation and neuronal avalanches analysis in networks of formal neurons. BMC Neuroscience 2011 12(Suppl 1):P172.

\section{Submit your next manuscript to BioMed Central} and take full advantage of:

- Convenient online submission

- Thorough peer review

- No space constraints or color figure charges

- Immediate publication on acceptance

- Inclusion in PubMed, CAS, Scopus and Google Scholar

- Research which is freely available for redistribution

Submit your manuscript at www.biomedcentral.com/submit
Biomed Central 